\title{
Effect of toasting and decortication of oat on rumen biohydrogenation and intestinal digestibility of fatty acids in dairy cows
}

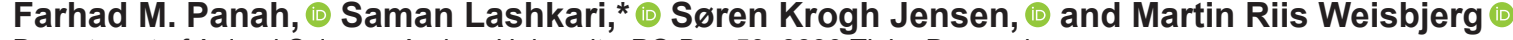 \\ Department of Animal Science, Aarhus University, PO Box 50, 8830 Tjele, Denmark
}

\begin{abstract}
This experiment quantified the effect of decorticated and toasted oat (Avena sativa L.) on fatty acid (FA) supply, ruminal biohydrogenation $(\mathrm{BH})$ of $\mathrm{FA}$, and intestinal digestibility of FA in 4 ruminal and intestinal cannulated Danish Holstein cows. Experimental diets containing untreated oat, decorticated oat, toasted oat, and decorticated and toasted oat were fed ad libitum to the cows in a $2 \times 2$ factorial arrangement in a Latin square design throughout 4 periods. Unless otherwise mentioned, the results of this study indicate the main effect of decortication and toasting. Decortication increased the intake of FA by $40.3 \mathrm{~g} / \mathrm{d}$ and increased feed-ileum digested FA, whereas toasting decreased the intake of FA by $69.3 \mathrm{~g} / \mathrm{d}$. Toasting increased both feedileum and total-tract digestibility of FA by 59.8 and $67.4 \mathrm{~g} / \mathrm{kg}$ of FA intake, respectively. The proportion of $\mathrm{C} 18: 2 \mathrm{n}-6$ in FA intake increased, and the C18:3n -3 proportion in FA intake decreased due to decortication. Toasting resulted in a dramatic reduction of the C18:2n-6 proportion in FA intake, and it increased the proportions of $\mathrm{C} 18: 0$ and $\mathrm{C} 18: 3 \mathrm{n}-3$ in FA intake. Toasting reduced ruminal $\mathrm{BH}$ of $\mathrm{C} 18: 1 \mathrm{n}-9$ and $\mathrm{C} 18: 2 \mathrm{n}$ -6 by 134 and $11.7 \mathrm{~g} / \mathrm{kg}$ of FA intake, respectively, and toasting increased the proportion of unsaturated FA to saturated FA in the duodenal FA flow. Decortication decreased the ruminal $\mathrm{BH}$ of $\mathrm{C} 18: 3 \mathrm{n}-3$ by $38.0 \mathrm{~g} / \mathrm{kg}$ of FA intake. Decortication increased small intestinal digestibility of C12:0, C15:0, C20:0, and C22:0. Toasting increased the small intestinal digestibility of C15:0, C18:0, trans-C18:1, C20:0, and C24:0. Toasting reduced the small intestinal digestibility of C18:1n-9, C18:2n -6 , and C20:1n-9. This study showed that decortication successfully increased the intake of FA and flow of FA at the duodenum and feed-ileum digested FA. However, toasting oat at $121^{\circ} \mathrm{C}$ caused a remarkable decline in FA concentration in oat, and thereby FA intake; therefore, toasting cannot be recommended.
\end{abstract}

Received December 25, 2019.

Accepted April 14, 2020.

*Corresponding author: Saman.l@anis.au.dk
Key words: dehulling, heat treatment, crude fat, unsaturated fatty acid, milk fatty acid, microbial fatty acid

\section{INTRODUCTION}

Organic dairying has limited possibilities for external inputs, such as concentrate (Blanco-Penedo et al., 2012; Scollan et al., 2017), which may restrict milk production and affect milk fatty acid (FA) composition (Schwendel et al., 2015). Compared with most cereals, oat has a high content of crude fat with high levels of PUFA (Decker et al., 2014; Qi et al., 2017). Oat is commonly grown by Nordic organic dairy farmers and could be used as a fat source for cows. However, oat grain is covered with hull (husk) and is low in crude fat (Welch et al., 1983) and high in structural carbohydrates and lignin (Round, 1988; Decker et al., 2014). Therefore, removing the hull through decortication increases the concentration of crude fat in oat (on DM basis) when compared with the husked grain. Increasing the fat content in the diet through decorticated oat might compromise the supply of AA because fat is not fermented in the rumen (Brask et al., 2015). However, Panah et al. (2020a) reported an increase in both microbial protein and AA synthesis due to decortication, possibly as a consequence of the increased starch intake concurrent with the increased fat content of oat by decortication. Toasting can protect protein against rumen degradation and then counteract the negative effect of increased fat supply on the metabolizable protein supply to the cow (Panah et al., 2020a). Gonthier et al. (2005) reported that heat treatment of oilseeds can protect the protein matrix surrounding the fat droplets against rumen degradation, and thereby protect UFA against ruminal biohydrogenation (BH). Panah et al. (2020a) showed that toasting oat reduced the ruminal digestibility of AA and in situ degradability of $\mathrm{CP}$, causing the increased flow of both $\mathrm{CP}$ and $\mathrm{AA}$ at the duodenum.

Upon entering the rumen, esterified FA undergo lipolysis by rumen microbes, and after lipolysis, UFA are extensively biohydrogenated in the rumen (Doreau 
and Chilliard, 1997). Decortication is expected to make the UFA of the grain more susceptible to ruminal $\mathrm{BH}$; therefore, partial protection against ruminal $\mathrm{BH}$ could increase the post ruminal appearance of UFA. Heat treatment was shown to be a successful approach in protecting UFA in different feeds from ruminal $\mathrm{BH}$ (Pires et al., 1997; Lashkari et al., 2015). This could also be applicable in oat because fat droplets are distributed throughout the endosperm together with starch and protein (Peterson and Wood, 1997). Therefore, the objective of this study was to investigate to what extent decortication could increase the FA supply, and if toasting could decrease ruminal BH of UFA.

\section{MATERIALS AND METHODS}

\section{Animals and Experimental Design}

This experiment complied with the Danish ethical requirements based on the Danish Ministry of Justice Law No. 726 (September 9, 1993). In a $4 \times 4$ Latin square design, 2 primiparous and 2 multiparous lactating Danish Holstein dairy cows, fitted with rumen cannulas and duodenal and ileal simple T-cannulas, received 1 of 4 experimental diets over 4 periods. Each period consisted of $22 \mathrm{~d}$, in which d 1 to 13 were allocated for adaptation, and d 13 to 17 for collection of digesta (i.e., rumen, duodenum, ileum, feces). The experimental diets were offered as TMR including whole grain oat (Oat), decorticated oat (D), toasted whole oat $(\mathbf{T})$, or decorticated toasted oat $(\mathbf{D T})$. The main effect of decortication and toasting is reported in full terms (i.e., decortication: the main effect of decortication in D and DT diets; toasting: the main effect of toasting in $\mathrm{T}$ and DT diets). Animals were housed in tie-stalls, and beds were covered with rubber mats and sawdust. The average BW of cows at the onset of the experiment was $618 \pm 47.9 \mathrm{~kg}$ (mean \pm standard deviation); the cows were at $61.3 \pm 49.9 \mathrm{~d}$ in milk, and their BCS was $3 \pm 0.20$ (mean \pm standard deviation). On d 17 through 22, the enteric methane emission was measured in respiration chambers, as already reported by Panah et al. (2020a).

\section{Diets and Feeding}

For the variety of oat used in this experiment, we used the 'Dominik' cultivar of Avena sativa grown in Denmark in 2017. We used a mobile decorticator with 3 Bühler dehuller MHSA (Bühler AG, Uzwil, Switzerland) mounted on a truck for decortication on-farm by Gl. Buurholt ApS (Brønderslev, Denmark), with an efficacy of $83 \%$, and the remainder was partially decorticated. Toasting at $121^{\circ} \mathrm{C}$ was done on-farm using a Bulldog Toaster (Mecmar S. p. a., Minerbe, Italy). The flow through the toaster was $2,500 \mathrm{~kg} / \mathrm{h}$, and the retention time was $35 \mathrm{~s}$. Before adding to the ration, all 4 forms of oat were rolled by a MS 1325-4 roller (Skjold, Sæby, Denmark) with a 3-mm roller distance.

Formulation of the diet was based on NorFor (Volden, 2011), and the forage-to-concentrate ratio of the TMR was 60:40 on a DM basis (Table 1). The TMR consisted $(\mathrm{g} / \mathrm{kg}$ of DM) of grass-clover silage (609), toasted fava beans (165), vitamin and mineral supplements (8.70), and oat ( 1 of the 4 forms; 217). Chemical composition of feedstuffs is presented in Table 2. The TMR was offered to the cows ad libitum twice daily at 0600 and 1630 h. Feed offered and residuals were recorded daily, and DM concentration of feed and residues was determined on d 12 through 17 in each period. Samples of all ingredients were taken in each period on a weekly basis. Analysis were performed on pooled samples for periods 1 and 2 , and for 3 and 4 , respectively.

\section{Rumen, Digesta, and Fecal Sampling}

Chromium oxide $\left(\mathrm{Cr}_{2} \mathrm{O}_{3} ; 10 \mathrm{~g}\right)$ and titanium dioxide $\left(\mathrm{TiO}_{2} ; 13 \mathrm{~g}\right)$ were used as digestion markers. Markers were weighed in degradable coffee filter bags and placed into the rumen concurrent with milking times (0520 and $1545 \mathrm{~h}$ ). Intestinal digesta and feces were sampled 12 times over 5 d (i.e., d 13-17: at $1000 \mathrm{~h}$ and $1800 \mathrm{~h}$ on d 13; $0200 \mathrm{~h}, 1200 \mathrm{~h}$, and $2000 \mathrm{~h}$ on d 14;0400 h, $1400 \mathrm{~h}$, and $2200 \mathrm{~h}$ on d 15; $0600 \mathrm{~h}, 1600 \mathrm{~h}$, and 2400 h on d 16; $0800 \mathrm{~h}$ on d 17). Plastic bags, mounted on L-shaped polyvinyl chloride pipe connectors, were used to collect duodenal (0.5-L) and ileal (0.2-L) samples

Table 1. Total mixed ration and nutrient composition of experimental diets, $\mathrm{g} / \mathrm{kg}$ of DM unless otherwise noted

\begin{tabular}{|c|c|c|c|c|}
\hline \multirow[b]{2}{*}{ Item } & \multicolumn{4}{|c|}{$\operatorname{Diet}^{1}$} \\
\hline & Oat & $\mathrm{D}$ & $\mathrm{T}$ & DT \\
\hline \multicolumn{5}{|l|}{ Ingredient } \\
\hline Whole oat grain & 217.1 & - & - & - \\
\hline Decorticated oat grain & - & 217.1 & - & - \\
\hline Toasted oat grain & - & - & 217.1 & - \\
\hline $\begin{array}{l}\text { Decorticated toasted } \\
\text { oat grain }\end{array}$ & - & - & - & 217.1 \\
\hline Toasted fava bean & 165.2 & 165.2 & 165.2 & 165.2 \\
\hline Grass-clover silage & 609 & 609 & 609 & 609 \\
\hline Mineral supplement & 8.70 & 8.70 & 8.70 & 8.70 \\
\hline \multicolumn{5}{|l|}{ Nutrients } \\
\hline $\mathrm{DM}, \mathrm{g} / \mathrm{kg}$ & 540 & 540 & 563 & 561 \\
\hline Ash & 77.6 & 77.4 & 77.8 & 77.4 \\
\hline Crude fat & 43.9 & 48.1 & 40.5 & 45.1 \\
\hline $\mathrm{CP}$ & 194 & 197 & 193 & 198 \\
\hline Starch & 156 & 175 & 151 & 174 \\
\hline NDF & 331 & 310 & 331 & 301 \\
\hline
\end{tabular}

${ }^{1}$ Oat $=$ whole grain oat; $\mathrm{D}=$ decorticated oat; $\mathrm{T}=$ toasted oat; $\mathrm{DT}=$ decorticated and toasted oat. 
from the T-cannula. Approximately $50 \mathrm{~g}$ of feces were collected either during defecation or from the rectum. The 12 samples for duodenal and ileal contents and feces were pooled by sample, by cow, and by period.

Microbes were isolated from the rumen fluid on $\mathrm{d} 17$ at $1200 \mathrm{~h}$. The isolation was carried out by collecting 2 $\mathrm{L}$ of rumen liquid from the ventral rumen. Liquid was filtered through 2 layers of cheese cloth into prewarmed thermos bottles. After being transferred to the laboratory, the samples were centrifuged twice at $500 \times g$ for $5 \mathrm{~min}$ at $3^{\circ} \mathrm{C}$ to remove feed particles and protozoa. Afterward, the resultant supernatant was centrifuged at $17,300 \times g$ for $20 \mathrm{~min}$ at $3^{\circ} \mathrm{C}$. The precipitated pellet was resuspended in $200 \mathrm{~mL}$ of saline solution $(0.9 \%$ $\mathrm{NaCl}$ ) and centrifuged at $17,300 \times g$ for 20 min at $3^{\circ} \mathrm{C}$ to harvest the pellet (microbial matter).

\section{Chemical Analysis}

Feed and digesta samples were stored frozen at $-20^{\circ} \mathrm{C}$ and subsequently freeze-dried before laboratory analysis. Dry matter of analyzed samples was determined by oven-drying at $60^{\circ} \mathrm{C}$ for $48 \mathrm{~h}$ according to Åkerlind et al. (2011). The ash content of feed was measured by combustion at $525^{\circ} \mathrm{C}$ for $6 \mathrm{~h}$. Chromium oxide in digesta and fecal output was oxidized to chromate and determined calorimetrically (Schürch et al., 1950). Titanium dioxide was digested with sulfuric acid, hydrogen peroxide was added, and absorbance was measured spectrophotometrically according to Myers et al. (2004), with the modification that $15 \mathrm{~mL}$ of
$30 \%$ hydrogen peroxide was added instead of $10 \mathrm{~mL}$, and an extra 5 drops of $30 \%$ hydrogen peroxide were added before absorbance measurement.

Microbial flow at the duodenum was estimated using purine as marker. Total purine was analyzed according to the method of Zinn and Owens (1986) with modification by Thode (1999).

Fat was extracted from $250 \mathrm{mg}$ of feed ingredient and feces, and $500 \mathrm{mg}$ of microbes and digesta, based on a modified HCl-Bligh and Dyer procedure (Bligh and Dyer, 1959; Jensen, 2008). After hydrolyzing the samples with $3 \mathrm{M} \mathrm{HCl}$ for $1 \mathrm{~h}$ at $80^{\circ} \mathrm{C}$, a mixture of $3 \mathrm{~mL}$ of methanol, $1.5 \mathrm{~mL}$ of distilled water, and 3 $\mathrm{mL}$ of chloroform, containing $5 \mathrm{mg}$ of C17:0 (hectadecanoic acid, Sigma-Aldrich, St. Louis, MO) as internal standard, was added. After shaking and phase separation by centrifugation, approximately $2 \mathrm{~mL}$ of the chloroform phase was transferred to tared tube, weighed, oven-dried at $100^{\circ} \mathrm{C}$, and weighed for total fat determination. Fatty acids from milk samples (0.50$\mathrm{mL}$ ) were extracted in the same way without prior acidic hydrolysis. Approximately $1 \mathrm{~mL}$ of the residual chloroform phase was transferred to a new culture tube (Wheaton, Millville, NJ; $16 \times 100 \mathrm{~mm}$; culture C-tubes with cap, round-bottom), evaporated to dryness under a $\mathrm{N}_{2}$ stream and methylated with $0.8 \mathrm{~mL} \mathrm{NaOH}(2 \%)$ in methanol, sealed with argon gas (Ar), and placed in an oven for $15 \mathrm{~min}$ at $100^{\circ} \mathrm{C}$. After cooling, $1 \mathrm{~mL}$ of boron trifluoride reagent was added with $\mathrm{Ar}$ and placed at $100^{\circ} \mathrm{C}$ for $45 \mathrm{~min}$. Finally, FA methyl esters were extracted with $2 \mathrm{~mL}$ of heptane and $4 \mathrm{~mL}$ of saturated

Table 2. Chemical composition and fatty acid profile of diet ingredients (mean $\pm \mathrm{SD}, \mathrm{n}=2$ ), $\mathrm{g} / \mathrm{kg}$ of DM unless noted

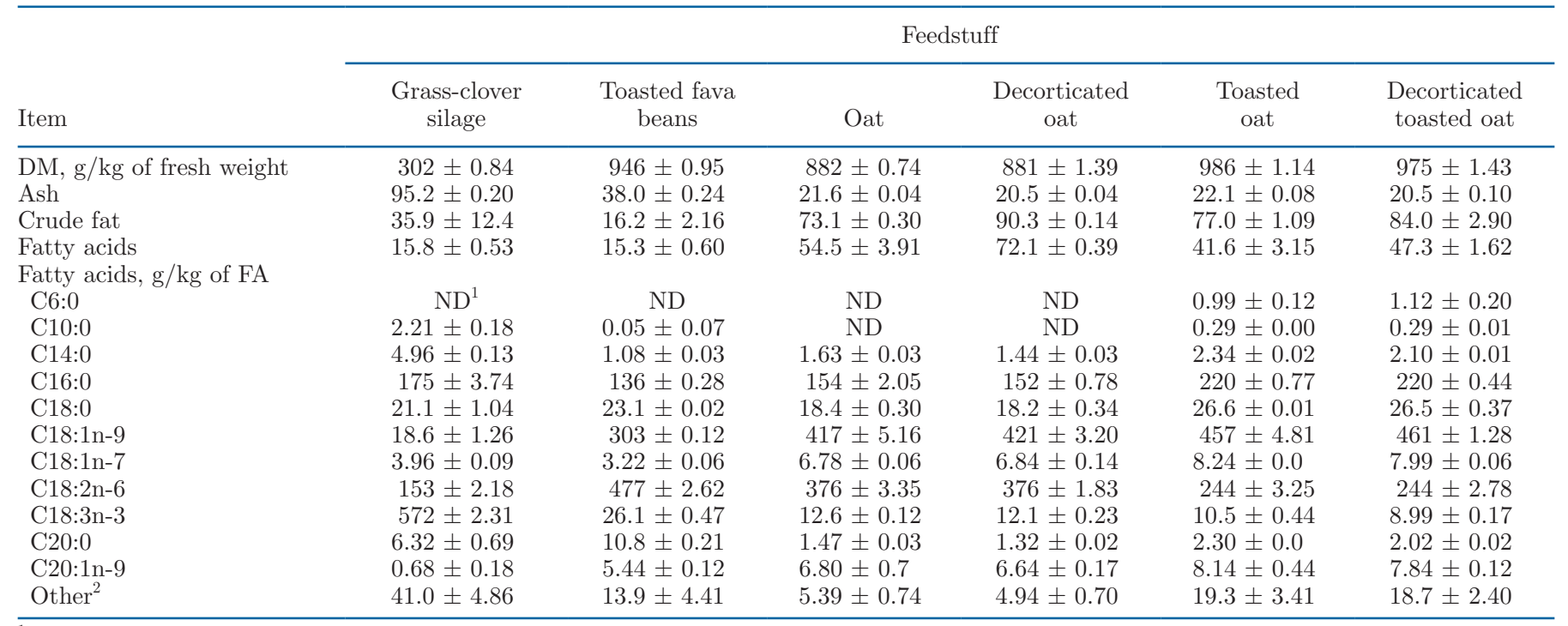

\footnotetext{
${ }^{1}$ Not detected.

${ }^{2}$ Sum of C8:0, C11:0, C12:0, C13:0, C14:1, C15:0, C16:1n-9, C16:1n-7, C17:1, trans-C18:1, C18:3n-6, C18:4n-3, cis-9, trans-11 CLA, trans10, cis-12 CLA, C20:2n-6, C20:3n-6, C20:4n-6, C20:3n-3, C20:5n-3, C22:0, C22:1n-11, C22:1n-9, C22:5n-6, C22:5n-3, C22:6n-3, C24:0, C24:1.
} 
$\mathrm{NaCl}$ solution, followed by centrifugation for $10 \mathrm{~min}$ at $2,000 \times g$ (Jensen, 2008). Microbial FA were analyzed both with and without internal standard. The gas chromatograph (Hewlett Packard 6890, Agilent Technologies, Palo Alto, CA) was equipped with an automatic column injector (Hewlett Packard 7673), a capillary column of $30 \mathrm{~m} \times 0.32 \mathrm{~mm}$ i.d., $0.25 \mu \mathrm{m}$ thickness (Omegawax 320, Supelco, Sigma-Aldrich), and a flame ionization detector for quantifying $\mathrm{FA}$ as FA methyl ester. The primary temperature was set at $170^{\circ} \mathrm{C}$, and the temperature was increased at a rate of $2^{\circ} \mathrm{C} / \mathrm{min}$ to $200^{\circ} \mathrm{C}$, held for $5 \mathrm{~min}$, and finally raised to $220^{\circ} \mathrm{C}$ at a rate of $5^{\circ} \mathrm{C} / \mathrm{min}$. Peaks were identified by comparison of retention times with external standards (GLC 68C, Nu-Prep Chek, Elysian, MN) for FA.

Cows were milked 2 times a day at 0520 and $1545 \mathrm{~h}$, and milk samples for FA analysis were taken from the evening on d 15 and morning on d 16 . The samples were mixed proportionally to milk production. For analysis of milk FA, milk samples were immediately frozen and kept cryopreserved until the day of analysis.

\section{Calculations and Statistical Analyses}

Dry matter intake was determined on d 12 through 17, and DMI data were averaged per cow per period. Daily DMI was calculated as DM offered minus DM in refusals. From d 13 to d 17 in each period, digesta DM flows were calculated as average of flows for each marker. Digestibility in the rumen, small intestine, and total-tract was calculated from the respective intake and flow at the duodenum, ileum, and fecal output.

The effect of different treatments on intake, digestibility, fat and FA content, and FA composition was analyzed using R (version 3.6.0, http://www.R-project .org). The least squares means of response variables were measured using the Fit Linear Mixed-Effects Models procedure in $\mathrm{R}$ through lmer function in lme4 package (Bates et al., 2015). The model was as below:

$$
Y_{i j k l}=\mu+D_{i}+T_{j}+D T_{i j}+P_{k}+C_{l}+E_{i j k l},
$$

where $Y$ is the dependent variable and $\mu$ is the overall mean; the model includes the fixed effects of decortication $\left(D_{i}\right)$, toasting $\left(T_{j}\right)$, the interaction $\left(D T_{i j}\right)$, and the $k$ th period $\left(P_{k}\right)$, the random effect of $l$ th cow $\left(C_{l}\right)$, and the random error $\left(E_{i j k l}\right)$. The main effects of decortication are reported as the effect of decortication in D and DT vs. Oat and T diets, and the main effect of toasting is based on the effects of toasting in $\mathrm{T}$ and $\mathrm{DT}$ vs. Oat and D diets. For the effect of internal standard on quantification of FA, the same model was used for statistical analysis with the inclusion of the effect of quantifications methods. Values presented in Tables 3-9 and in Supplemental Tables S1-S4 (https://doi .org/10.3168/jds.2019-18125) are least squares means with corresponding standard error of the mean. Significance for main effects was declared at $P \leq 0.05$ and a tendency at $0.05<P<0.10$. Interaction at $P \leq 0.05$ was declared significant, and if significant, least squares means were compared using the Tukey-Kramer test at $\alpha=0.05$.

\section{RESULTS}

\section{Intake}

Crude fat intake did not change, but FA intake increased due to decortication by $40.3 \mathrm{~g} / \mathrm{d}$ (as a difference between decorticated oat and nondecorticated oat; $P=0.02)$, and toasting decreased FA intake by 69.3 $\mathrm{g} / \mathrm{d}(P<0.01 ;$ Table 3$)$. Decortication increased the total-tract digested amount of fat $(P=0.05)$.

Decortication decreased the proportion of C10:0 and C14:0 intake in total FA intake and tended to decrease the C18:0 proportion, whereas toasting increased their proportion as well as the C16:0 proportion in total FA intake (Table 4). The proportion of C18:1n-9 in FA intake increased $(P<0.01)$ due to decortication and decreased $(P<0.01)$ by toasting. Decortication increased the proportion of C18:2n-6, and it decreased the C18: $3 n-3$ proportion, and toasting reduced the proportion of C18:2n- 6 and increased the $\mathrm{C} 18: 3 \mathrm{n}-3$ proportion in FA intake. Decortication increased the ratio of UFA:SFA, and toasting decreased this ratio in FA intake.

\section{Digested Amount and Digestibility}

Feed-ileum digestibility of crude fat increased $(P$ $=0.01)$ by decortication. The $\mathrm{D}$ diet showed higher feed-ileum digestibility of crude fat compared with Oat diet (559 vs. $501 \mathrm{~g} / \mathrm{kg}$ of fat intake; interaction $P<$ 0.01; Table 3). However, neither the total-tract nor the hindgut digestibility of crude fat were affected by treatments. Decortication tended to increase FA digested in the small intestine, and it increased the feed-ileum digested FA by $35.9 \mathrm{~g} / \mathrm{d}(P=0.01)$. The amount of feed-ileum digested FA was reduced by $29.0 \mathrm{~g} / \mathrm{d}(P=$ $0.03)$ due to toasting. Total-tract digested FA increased by decortication $(P=0.03)$, and it decreased by toasting $(P=0.04)$. Toasting increased the small intestinal digestibility of FA by $67.0 \mathrm{~g} / \mathrm{kg}$ of duodenal FA $(P<$ 0.01 ), and increased the feed-ileum FA digestibility by $59.8 \mathrm{~g} / \mathrm{kg}$ of FA intake $(P=0.01)$. Total-tract digestibility of FA was increased by $67.4 \mathrm{~g} / \mathrm{kg}$ of FA intake $(P$ $=0.01$ ), owing to toasting. 
Ruminal formation of C18:0 decreased by $71.3 \mathrm{~g} / \mathrm{d}$ $(P<0.01)$ due to toasting (Table 5$)$. Toasting reduced the ruminal disappearance of $\mathrm{C} 18: 1 \mathrm{n}-9$ by $36.0 \mathrm{~g} / \mathrm{d}(P$ $<0.01)$, and decortication increased it by $15.6 \mathrm{~g} / \mathrm{d}(P$ $=0.01)$. The ruminal formation of trans-C18:1 was reduced by toasting $(P=0.01)$ and increased by decortication $(P=0.04)$. Toasting resulted in lower ruminal disappearance of $\mathrm{C} 18: 2 \mathrm{n}-6$ by $58.0 \mathrm{~g} / \mathrm{d}(P<0.01)$.

Toasting reduced the ruminal $\mathrm{BH}$ of $\mathrm{C} 18: 1 \mathrm{n}-9(P<$ $0.01)$ and $\mathrm{C} 18: 2 \mathrm{n}-6(P=0.01)$ by 134 and $11.7 \mathrm{~g} / \mathrm{kg}$ of FA intake, respectively (Table 5). Decortication decreased the ruminal BH of C18:3n-3 by $38.0 \mathrm{~g} / \mathrm{kg}$ of FA. The DT diet yielded the lowest BH for C18:1n-9 when compared with Oat, $\mathrm{D}$, and $\mathrm{T}$ (interaction $P=0.02$ ).

Decortication reduced the proportion of C15:0, C18:1n-9, C18:3n-3, C22:0, C24:0, and odd chain FA (OCFA) in the duodenal FA (Supplemental Table S1, https://doi.org/10.3168/jds.2019-18125). Toasting increased the proportion of C15:0, C16:0, C18:1n-9, C18:2n-6, C18:3n-3, C20:0, C22:0, C24:0, and OCFA, whereas it decreased C18:0 in the duodenal FA.
Decortication increased the small intestinal digestibility of C12:0, C15:0, C20:0, and C22:0, and tended to increase the C13:0 digestibility (Table 6). Toasting increased the small intestinal digestibility of $\mathrm{C} 15: 0$, $\mathrm{C} 18: 0$, trans-C18:1, C24:0, and C20:0, and tended to increase the $\mathrm{C} 22: 0$ digestibility. Toasting reduced the small intestinal digestibility of C18:1n-9 and C18:2n-6. Compared with Oat, D, and T diets, DT resulted in the highest reduction of the small intestinal digestibility of C18:1n-9 and C18:2n-6; digestibilities were 759 and $838 \mathrm{~g} / \mathrm{kg}$, respectively. Toasting reduced the digested amount of trans-C18:1 in the small intestine, with a tendency to reduce it for C18:0 (Supplemental Table S2, https://doi.org/10.3168/jds.2019-18125).

The total-tract digestibility of C18:2n-9, C18:2n-6, and C18:3n-3 increased by decortication (Table 7). Toasting increased the total-tract digestibility of SFA, such as C12:0, C15:0, C16:0, C18:0, C20:0, C22:0, and C24:0, while it decreased that for UFA, such as C18:1n -9 , C18:2n-6, and C18:3n-3. The hindgut digestibility of SFA, including C18:0, C20:0, and C24:0, was reduced

Table 3. Intake and rumen, intestine, hindgut, and total-tract digestibilities ${ }^{1}$ of crude fat and total fatty acids and daily digested amounts

\begin{tabular}{|c|c|c|c|c|c|c|c|c|}
\hline \multirow[b]{2}{*}{ Item } & \multicolumn{4}{|c|}{ Diet $^{2}$} & \multirow[b]{2}{*}{ SEM } & \multicolumn{3}{|c|}{$P$-value ${ }^{3}$} \\
\hline & Oat & $\mathrm{D}$ & $\mathrm{T}$ & DT & & Dec & Toa & Dec $\times$ Toa \\
\hline $\mathrm{DM}, \mathrm{kg} / \mathrm{d}$ & 21.7 & 20.7 & 22.0 & 21.9 & 2.07 & 0.25 & 0.08 & 0.25 \\
\hline Crude fat, $\mathrm{g} / \mathrm{d}$ & 896 & 913 & 892 & 943 & 89.0 & 0.19 & 0.59 & 0.49 \\
\hline $\mathrm{FA},{ }^{4} \mathrm{~g} / \mathrm{d}$ & 521 & 577 & 468 & 491 & 53.1 & 0.02 & $<0.01$ & 0.24 \\
\hline \multicolumn{9}{|c|}{ Digested crude fat, $\mathrm{g} / \mathrm{d}$} \\
\hline Hindgut & -91.0 & -109 & -136 & -73.8 & 28.4 & 0.44 & 0.86 & 0.19 \\
\hline Total tract & 384 & 411 & 347 & 434 & 49.0 & 0.05 & 0.76 & 0.24 \\
\hline \multicolumn{9}{|c|}{ Digestibility of crude fat, $\mathrm{g} / \mathrm{kg}$ of fat } \\
\hline Rumen & $-1,103$ & $-1,046$ & $-1,129$ & $-1,096$ & 74.5 & 0.38 & 0.45 & 0.80 \\
\hline Small intestine & 765 & 784 & 783 & 776 & 13.0 & 0.38 & 0.40 & 0.08 \\
\hline Feed-ileum & $501^{\mathrm{a}}$ & $559^{\mathrm{b}}$ & $542^{\mathrm{b}}$ & $528^{\mathrm{ab}}$ & 23.1 & 0.04 & 0.56 & $<0.01$ \\
\hline Hindgut & -236 & -266 & -333 & -167 & 64.8 & 0.32 & 0.99 & 0.17 \\
\hline Hindgut & 11.0 & 2.73 & 9.52 & 7.54 & 4.83 & 0.31 & 0.73 & 0.52 \\
\hline Total tract & 414 & 462 & 403 & 416 & 50.6 & 0.03 & 0.04 & 0.16 \\
\hline \multicolumn{9}{|c|}{ Digestibility of total FA, $\mathrm{g} / \mathrm{kg}$ of FA } \\
\hline Rumen & 102 & 97.9 & 106 & 64.3 & 44.0 & 0.58 & 0.68 & 0.65 \\
\hline Small intestine & 739 & 771 & 822 & 822 & 18.7 & 0.29 & $<0.01$ & 0.29 \\
\hline Feed-ileum & 762 & 794 & 841 & 834 & 23.3 & 0.48 & 0.01 & 0.28 \\
\hline Hindgut & 89.5 & 19.2 & 129 & 90.0 & 28.6 & 0.09 & 0.09 & 0.59 \\
\hline Total tract & 781 & 797 & 863 & 850 & 22.0 & 0.92 & 0.01 & 0.39 \\
\hline
\end{tabular}

${ }^{\mathrm{a}, \mathrm{b}}$ Means in the same row with different superscripts differ $(P \leq 0.05)$.

${ }^{1}$ Digestibility values in rumen, small intestine, hindgut, and total tract are reported in grams of digested fat or fatty acid (FA) per kg of fat or FA intake, duodenal flow, ileal flow, and intake, respectively. Negative digestibilities indicate a supply of crude fat in the respective section, for rumen digestibilities probably due to supply of bile acids.

${ }^{2}$ Oat $=$ whole grain oat $\mathrm{D}=$ decorticated oat; $\mathrm{T}=$ toasted oat; $\mathrm{DT}=$ decorticated and toasted oat.

${ }^{3}$ Dec $=$ effect of decortication; Toa $=$ effect of toasting; Dec $\times$ Toa $=$ interaction between toasting and decortication.

${ }^{4}$ It was assumed that the FA content of the feed refusals equals FA content in the intake because diets were offered as TMR. 
Table 4. Composition of total fatty acid (FA) intake ( $\mathrm{g} / \mathrm{kg}$ of FA intake)

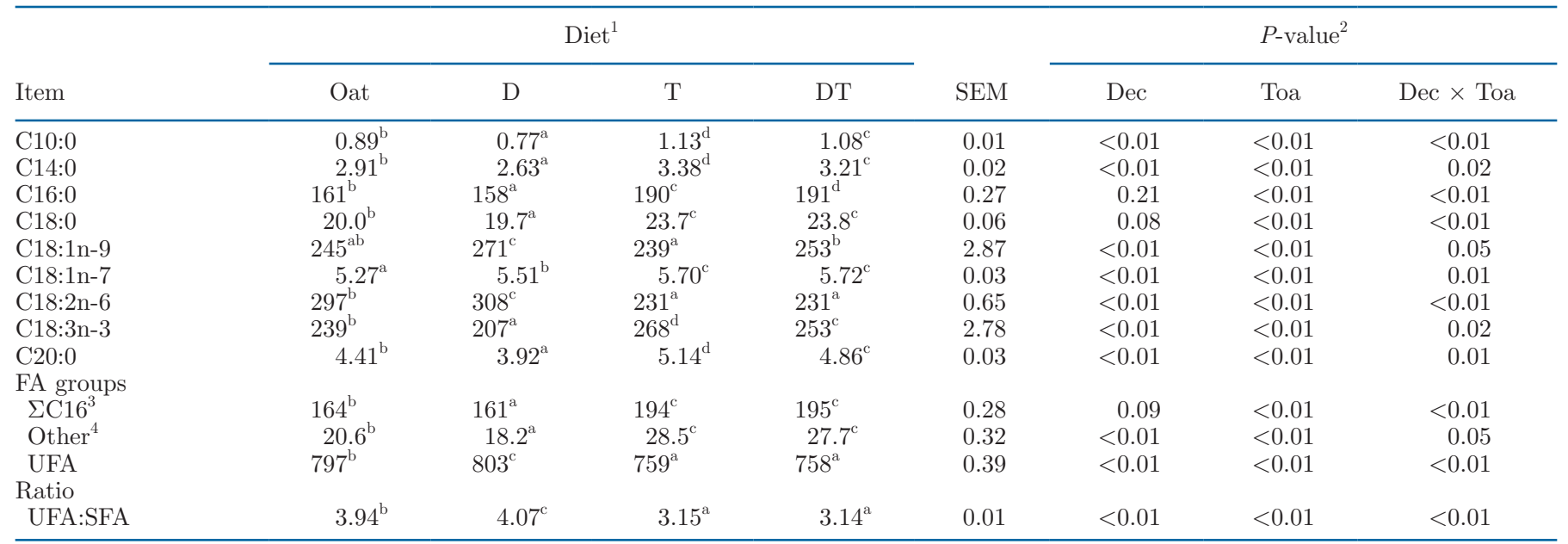

${ }^{\mathrm{a}-\mathrm{d}}$ Means in the same row with different superscripts differ $(P \leq 0.05)$.

${ }^{1}$ Oat $=$ whole grain oat; $\mathrm{D}=$ decorticated oat; $\mathrm{T}=$ toasted oat; $\mathrm{DT}=$ decorticated and toasted oat.

${ }^{2}$ Dec $=$ effect of decortication; Toa $=$ effect of toasting; Dec $\times$ Toa $=$ interaction between toasting and decortication.

${ }^{3} \Sigma(\mathrm{C} 16: 0, \mathrm{C} 16: 1 \mathrm{n}-9, \mathrm{C} 16: 1 \mathrm{n}-7)$.

${ }^{4}$ Sum of C6:0, C8:0, C11:0, C12:0, C13:0, C14:1, C15:0, C17:1, trans-C18:1, C18:3n-6, C18:4n-3, cis-9,trans-11 CLA, trans-10,cis-12 CLA, C20: 1n-9, C20:2n-6, C20:3n-6, C20:4n-6, C20:3n-3, C20:5n-3, C22:0, C22:1n-11, C22:1n-9, C22:5n-6, C22:5n-3, C24:0, C22:6n-3, C24:1.

Table 5. Ruminal disappearance ${ }^{1}(\mathrm{~g} / \mathrm{d})$ and fatty acid (FA) biohydrogenation ${ }^{2}(\mathrm{~g} / \mathrm{kg}$ of FA intake)

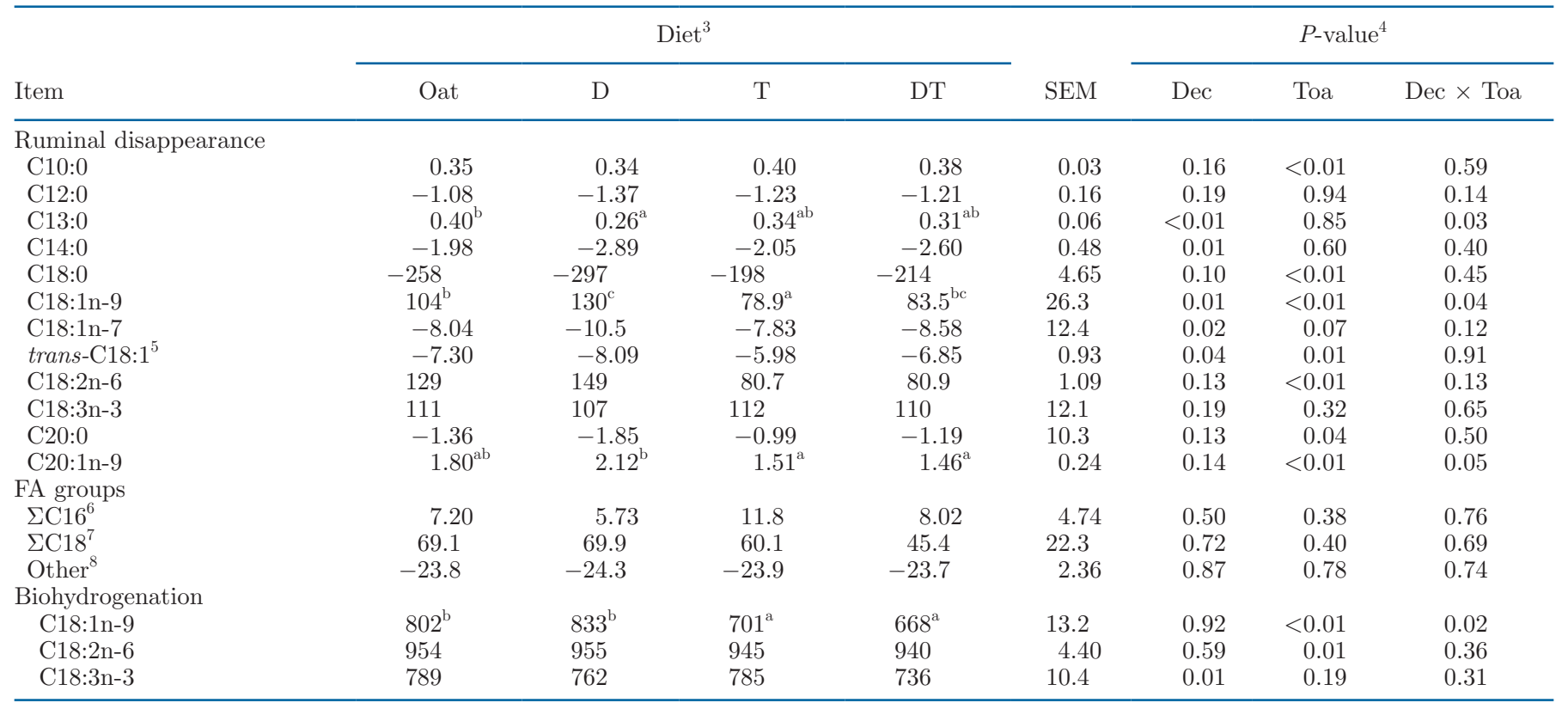

${ }^{\mathrm{a}-c}$ Means in the same row with different superscripts differ $(P \leq 0.05)$.

${ }^{1}$ Ruminal disappearance was measured as: FA intake - duodenal FA flow.

${ }^{2}$ Ruminal biohydrogenation: (FA intake - FA in duodenal flow)/FA intake.

${ }^{3}$ Oat $=$ whole grain oat; $\mathrm{D}=$ decorticated oat; $\mathrm{T}=$ toasted oat; $\mathrm{DT}=$ decorticated and toasted oat.

${ }^{4}$ Dec $=$ effect of decortication; Toa $=$ effect of toasting; Dec $\times$ Toa $=$ interaction between toasting and decortication.

${ }^{5}$ All trans-C18:1, mainly vaccenic acid.

${ }^{6} \Sigma(\mathrm{C} 16: 0, \mathrm{C} 16: 1 \mathrm{n}-9, \mathrm{C} 16: 1 \mathrm{n}-7)$.

${ }^{7} \Sigma(\mathrm{C} 18: 0, \mathrm{C} 18: 1 \mathrm{n}-9$, C18:1n-7, trans-C18:1, C18:2n-6, C18:3n-6, C18:3n-3, C18:4n-3, cis-9,trans-11 CLA, trans-10, cis-12 CLA).

${ }^{8}$ Sum of C6:0, C8:0, C11:0, C14:1, C15:0, C17:1, C18:3n-6, C18:4n-3, cis-9,trans-11 CLA, trans-10, cis-12 CLA, C20:2n-6, C20:3n-6, C20:4n-6, C20:3n-3, C20:5n-3, C22:0, C22:1n-11, C22:1n-9, C22:5n-6, C22:5n-3, C24:0, C22:6n-3, C24:1. 
Table 6. Small intestinal digestibility of fatty acids ( $\mathrm{g} / \mathrm{kg}$ of duodenal fatty acid flow)

\begin{tabular}{|c|c|c|c|c|c|c|c|c|}
\hline \multirow[b]{2}{*}{ Item } & \multicolumn{4}{|c|}{$\operatorname{Diet}^{1}$} & \multirow[b]{2}{*}{ SEM } & \multicolumn{3}{|c|}{$P$-value ${ }^{2}$} \\
\hline & Oat & $\mathrm{D}$ & $\mathrm{T}$ & DT & & Dec & Toa & Dec $\times$ Toa \\
\hline C11:0 & 824 & 735 & 655 & 715 & 50.0 & 0.79 & 0.09 & 0.17 \\
\hline C12:0 & 606 & 684 & 651 & 665 & 21.5 & 0.05 & 0.50 & 0.15 \\
\hline C13:0 & 462 & 533 & 438 & 529 & 42.2 & 0.09 & 0.75 & 0.82 \\
\hline C14:0 & 742 & 757 & 752 & 771 & 14.9 & 0.28 & 0.46 & 0.89 \\
\hline C15:0 & 772 & 806 & 817 & 830 & 10.3 & 0.04 & 0.01 & 0.34 \\
\hline C16:0 & 807 & 837 & 830 & 828 & 11.0 & 0.21 & 0.53 & 0.16 \\
\hline C16:1n-9 & 822 & 755 & 813 & 751 & 76.8 & 0.38 & 0.93 & 0.97 \\
\hline C16:1n-7 & 967 & 982 & 903 & 955 & 32.3 & 0.33 & 0.19 & 0.58 \\
\hline C17:1 & 923 & 930 & 913 & 928 & 7.36 & 0.16 & 0.40 & 0.55 \\
\hline C18:0 & 688 & 726 & 826 & 831 & 27.4 & 0.29 & $<0.01$ & 0.40 \\
\hline C18:1n-9 & $874^{\mathrm{b}}$ & $892^{\mathrm{b}}$ & $798^{\mathrm{a}}$ & $759^{\mathrm{a}}$ & 8.33 & 0.24 & $<0.01$ & 0.01 \\
\hline C18:1n-7 & 843 & 876 & 875 & 878 & 9.87 & 0.11 & 0.14 & 0.18 \\
\hline trans-C18: $1^{3}$ & 839 & 871 & 907 & 908 & 16.1 & 0.28 & 0.01 & 0.31 \\
\hline C18:2n-6 & $857^{\mathrm{ab}}$ & $880^{\mathrm{b}}$ & $858^{\mathrm{ab}}$ & $838^{\mathrm{a}}$ & 8.91 & 0.93 & 0.05 & 0.04 \\
\hline C18:3n-3 & 858 & 874 & 858 & 867 & 9.44 & 0.22 & 0.76 & 0.73 \\
\hline C20:0 & 602 & 663 & 694 & 736 & 23.5 & 0.04 & 0.01 & 0.63 \\
\hline C20:1n-9 & 749 & 892 & 553 & 695 & 89.7 & 0.13 & 0.05 & 1.00 \\
\hline C20:3n-6 & 953 & 969 & 971 & 973 & 9.61 & 0.28 & 0.18 & 0.38 \\
\hline C20:4n-6 & 965 & 971 & 953 & 954 & 15.2 & 0.72 & 0.20 & 0.84 \\
\hline C20:5n-3 & 970 & 956 & 957 & 969 & 20.0 & 0.95 & 0.98 & 0.52 \\
\hline C22:0 & 535 & 590 & 586 & 647 & 25.3 & 0.05 & 0.06 & 0.91 \\
\hline C22:5n-3 & 956 & 971 & 972 & 966 & 12.7 & 0.68 & 0.65 & 0.38 \\
\hline C24:0 & 488 & 560 & 565 & 634 & 34.5 & 0.06 & 0.05 & 0.96 \\
\hline $\mathrm{C} 24: 1$ & 731 & 798 & 641 & 822 & 123 & 0.32 & 0.78 & 0.63 \\
\hline Other ${ }^{4}$ & 490 & 584 & 672 & 699 & 100 & 0.53 & 0.16 & 0.72 \\
\hline
\end{tabular}

$\overline{\mathrm{a}, \mathrm{b}}$ Means in the same row with different superscripts differ $(P \leq 0.05)$.

${ }^{1}$ Oat $=$ whole grain oat; $\mathrm{D}=$ decorticated oat; $\mathrm{T}=$ toasted oat; $\mathrm{DT}=$ decorticated and toasted oat.

${ }^{2}$ Dec $=$ effect of decortication; Toa $=$ effect of toasting; Dec $\times$ Toa $=$ interaction between toasting and decortication.

${ }^{3}$ All trans-C18:1, mainly vaccenic acid.

${ }^{4}$ Sum of C6:0, C8:0, C10:0, C14:1, C18:3n-6, C18:4n-3, cis-9,trans-11 CLA, trans-10,cis-12 CLA, C20:2n-6, C20:3n-3, C22:1n-11, C22:1n-9, C22:5n-6, C22:6n-3.

by decortication. Toasting increased hindgut digestibility of C18:1n-9 and trans-C18:1 (Supplemental Table S3, https://doi.org/10.3168/jds.2019-18125). The major part of fecal FA consisted of C16:0 and C18:0, 170 and $605 \mathrm{~g} / \mathrm{kg}$ of fecal FA, respectively (data are not presented).

\section{Microbial and Duodenal Fatty Acid Composition}

Decortication had a tendency to reduce the proportion of C18:3n-3 in microbial FA (Table 8). Toasting decreased the proportion of $\mathrm{C} 18: 0$ with a tendency to reduce $\mathrm{C} 18: 1 \mathrm{n}-9$, while it increased the proportion of C18:3n-3 $(P<0.01)$ and OCFA in microbial FA. The n-6:n-3 ratio increased $(P=0.03)$ with decortication and decreased $(P<0.01)$ with toasting, due to possible oxidation.

Supplemental Table S4 (https://doi.org/10.3168/jds .2019-18125) shows the quantification of microbial FA with and without adjustment for the native amount of C17:0 as internal standard. No significant difference was found in the amount of $\mathrm{C} 16: 0$ and $\mathrm{C} 18: 0$, with and without adjustment for the native amount of C17:0. Similarly, the quantities of C18:1n-9, C18:2n-6, and C18:3n-3 were not affected by adjustment for the native amount of $\mathrm{C} 17: 0$.

\section{Milk Fatty Acid Composition}

There tended to be an interaction between decortication and toasting, resulting in an increased proportion of C18:3n-6 in milk FA in DT (Table 9). Decortication increased the proportion of $\mathrm{C} 20: 2 \mathrm{n}-6(P<0.01)$ in milk FA.

\section{DISCUSSION}

\section{Intake}

Intake of FA increased by decortication due to removal of the hull with low FA concentration. Oat hull accounts for 25 to $30 \%$ of the whole grain DM (Butt et al., 2008), and according to Welch et al. (1983), it contains only 10.0 to $22.0 \mathrm{~g}$ of crude fat and 1.70 to $4.70 \mathrm{~g}$ 
Table 7. Total-tract digestibility ${ }^{1}$ of fatty acids (FA; $\mathrm{g} / \mathrm{kg}$ of total FA intake)

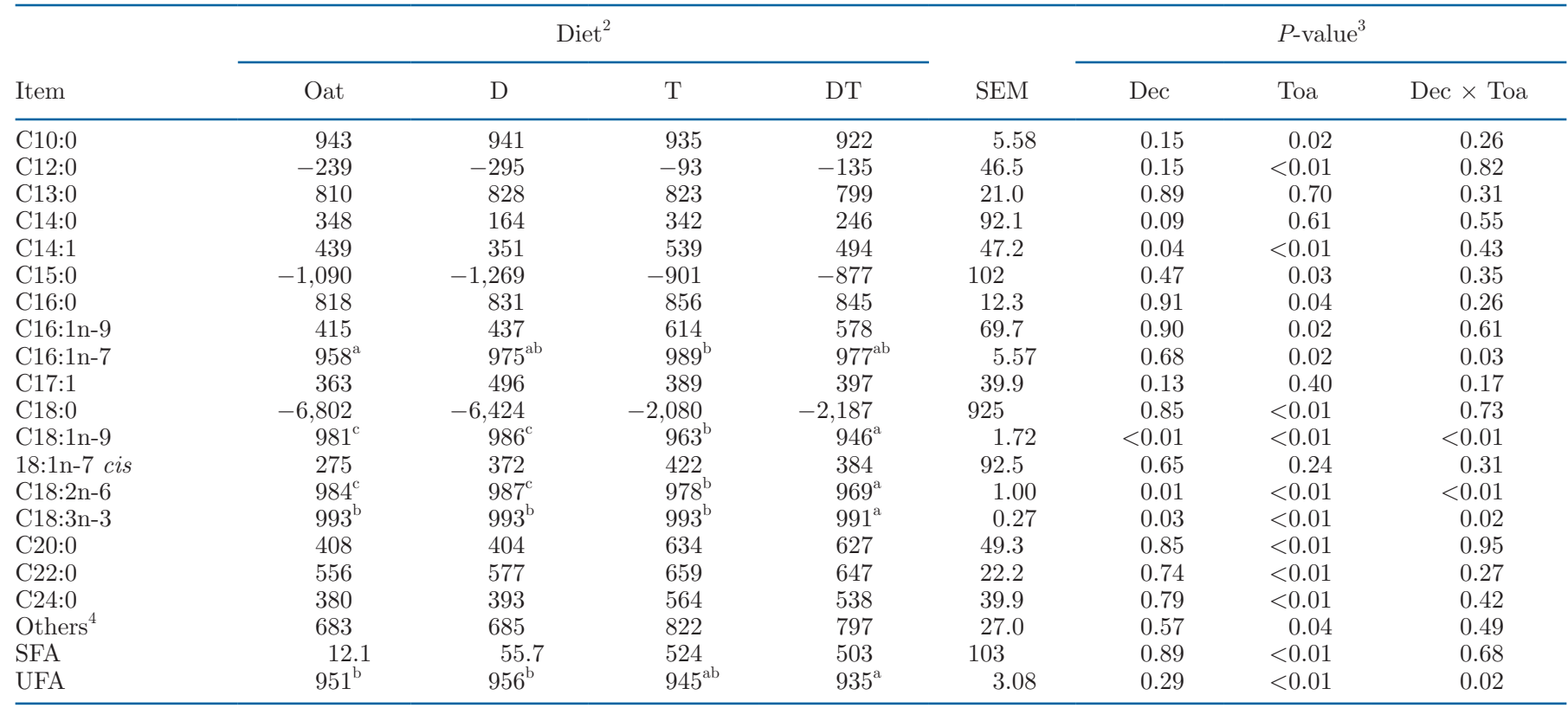

${ }^{\mathrm{a}-\mathrm{c}}$ Means in the same row with different superscripts differ $(P \leq 0.05)$.

${ }^{1}$ Total-tract digestibility of FA: (FA intake - FA in fecal output)/FA intake $\times 1,000$.

${ }^{2}$ Oat $=$ whole grain oat; $\mathrm{D}=$ decorticated oat; $\mathrm{T}=$ toasted oat; $\mathrm{DT}=$ decorticated and toasted oat.

${ }^{3}$ Dec $=$ effect of decortication; Toa $=$ effect of toasting; Dec $\times$ Toa $=$ interaction between toasting and decortication.

${ }^{4}$ Sum of C6:0, C8:0, C11:0, C18:3n-6, C18:4n-3, trans-C18:1, cis-9,trans-11 CLA, trans-10,cis-12 CLA, C20:1n-9, C20:3n-3, C20:5n-3, C20:2n-6, C20:3n-6, C20:4n-6, C22:1n-11, C22:1n-9, C22:5n-6, C22:6n-3.

of FA per $\mathrm{kg}$ of DM. The C16:0 and Cl8:0 proportions of FA were higher, and the proportions of C18:1n-9 and C18:2n- 6 were lower in oat hull compared with the grain in the study by Welch et al. (1983). Therefore, the FA composition in hull compared with whole oat explains the effect of decortication on FA composition of diets containing undecorticated oat. In agreement with the present findings, Panah et al. (2020b) also reported an increased FA content in decorticated oat. Therefore, decortication of oat is a tool to increase the concentration of FA in the ration.

The proportion of C16:0, C18:0 and C18:1 increased in Oat due to toasting in agreement with Molteberg et al. (1995), who reported that heat treatment increased the proportion of C18:0 in total FA of oat and decorticated oat, mainly due to the nonenzymatic oxidation of PUFA and the destruction of antioxidants during the heat treatment. Despite a slightly increased DMI, toasting decreased the FA intake mainly due to the reduction of $\mathrm{C} 18: 2 \mathrm{n}-6$ and $\mathrm{C} 18: 3 \mathrm{n}-3$ concentrations in toasted oat (both $\mathrm{T}$ and DT; as a difference between toasted oat and nontoasted oat) with an average of 12.9 and $0.35 \mathrm{~g} / \mathrm{kg}$ of DM, respectively (Table 1). This reduction of C18:2n- 6 and C18:3n-3 due to toasting was not expected because we anticipated that toasting, by denaturing the protein matrix around the fat droplets, would encapsulate the UFA (Kennelly, 1996; Gonthier et al., 2005), as a big portion of oat fat is stored in the endosperm in combination with protein (Peterson and Wood, 1997). Martin (1958) reported that oat fat is susceptible to heat-induced oxidation, owing to its high levels of UFA. Accordingly, Lampi et al. (2015) showed that when raising the temperature from 110 to $130^{\circ} \mathrm{C}$ during heat treatment (extrusion), the oat flour promoted a nonenzymatic oxidation of oat lipids followed by a decrease in total FA $(15.2 \%)$, C18:1n-9 (11.1\%) and C18:2n-6 (21.1\%) concentrations, and accumulation of oxidation byproducts during prolonged storage. Likewise, in the present study, toasting oat decreased the total FA $(18.8 \mathrm{~g} / \mathrm{kg}$ of DM) and C18:2n-6 (132 g/kg of FA). The concentration of C18:1n-9 also decreased in DM; however, due to the serious decrease, especially in $\mathrm{C} 18: 2 \mathrm{n}-6$, the proportion of $\mathrm{C} 18: 1 \mathrm{n}-9$ in total FA increased $(40.0 \mathrm{~g} / \mathrm{kg}$ of FA) by toasting.

Molteberg et al. (1995) showed that in corn flakes, the antioxidant activity of tocopherols hindered the oxidation of FA in extruded corn flakes. It was later confirmed that heat treatment at 120,160 , and $200^{\circ} \mathrm{C}$ was associated with a significant reduction of vitamin E in wheat, barley, rye, and oat (Hall, 2010), leading to nonenzymatic oxidation during storage (Martin, 1958). Nonetheless, there is a void of studies about the effect 
Table 8. Ruminal microbial synthesis of fat and fatty acid (g/d), and microbial fatty acid (FA) composition

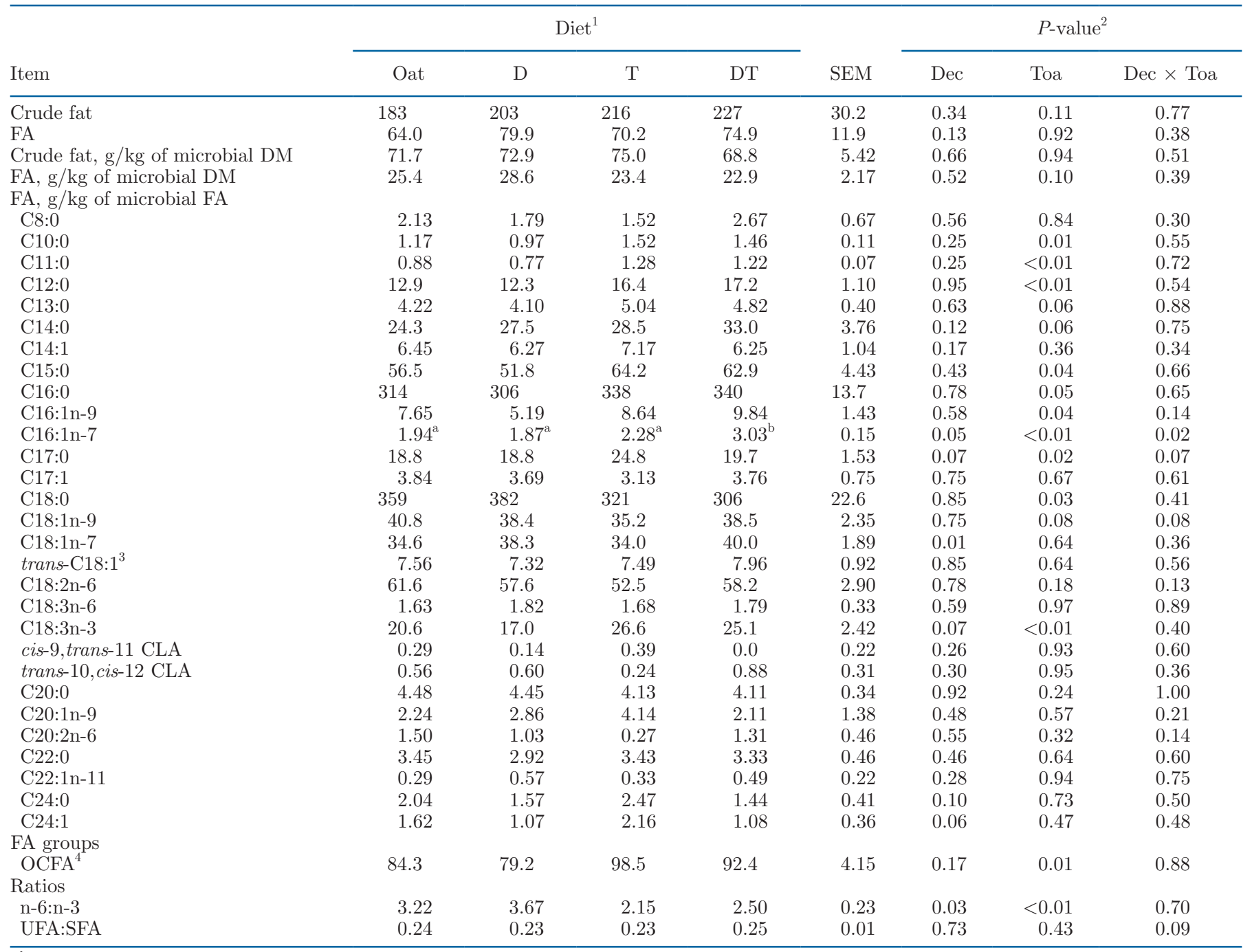

a,b Means in the same row with different superscripts differ $(P \leq 0.05)$.

${ }^{1}$ Oat $=$ whole grain oat; $\mathrm{D}=$ decorticated oat; $\mathrm{T}=$ toasted oat; $\mathrm{DT}=$ decorticated and toasted oat.

${ }^{2}$ Dec $=$ effect of decortication; Toa $=$ effect of toasting; Dec $\times$ Toa $=$ interaction between toasting and decortication.

${ }^{3}$ All trans-C18:1, mainly vaccenic acid.

${ }^{4} \mathrm{OCFA}=$ odd-chain FA.

of toasting oat on its FA concentration during the application of heat treatment because the main focus has been the effect of heat on oat lipids during storage of oat products for human consumption. Therefore, in the present study, it is difficult to attribute the reduced total FA, and especially C18:2n-6, to either nonenzymatic oxidation of FA or inactivation of antioxidants or both during toasting. However, the decrease in FA concentration in this study was large enough to make toasting at temperatures required for protein protection irrelevant for oat, as the potential gain in protein value (Panah et al., 2020a) is overruled by the decrease in crude fat and FA, and thereby energy value, of oat.

\section{Digested Amount and Digestibility}

Although toasting increased the FA digestibility in the small intestine and in both the feed-ileum and total-tract, it decreased the amount of feed-ileum and total-tract digested FA due to reduced FA intake by toasting. The observed values for feed-ileum digestibility of FA were numerically lower than those for total-tract digestibility of FA. Hindgut digestibility values for FA were higher than zero $(P=0.05)$ for all diets except for $\mathrm{D}$, indicating that there is an overall digestion of FA in the hindgut. Other studies reported discrepancies between feed-ileum and total-tract digest- 
Table 9. Milk fatty acids (FA) composition ( $\mathrm{g} / \mathrm{kg}$ of milk FA)

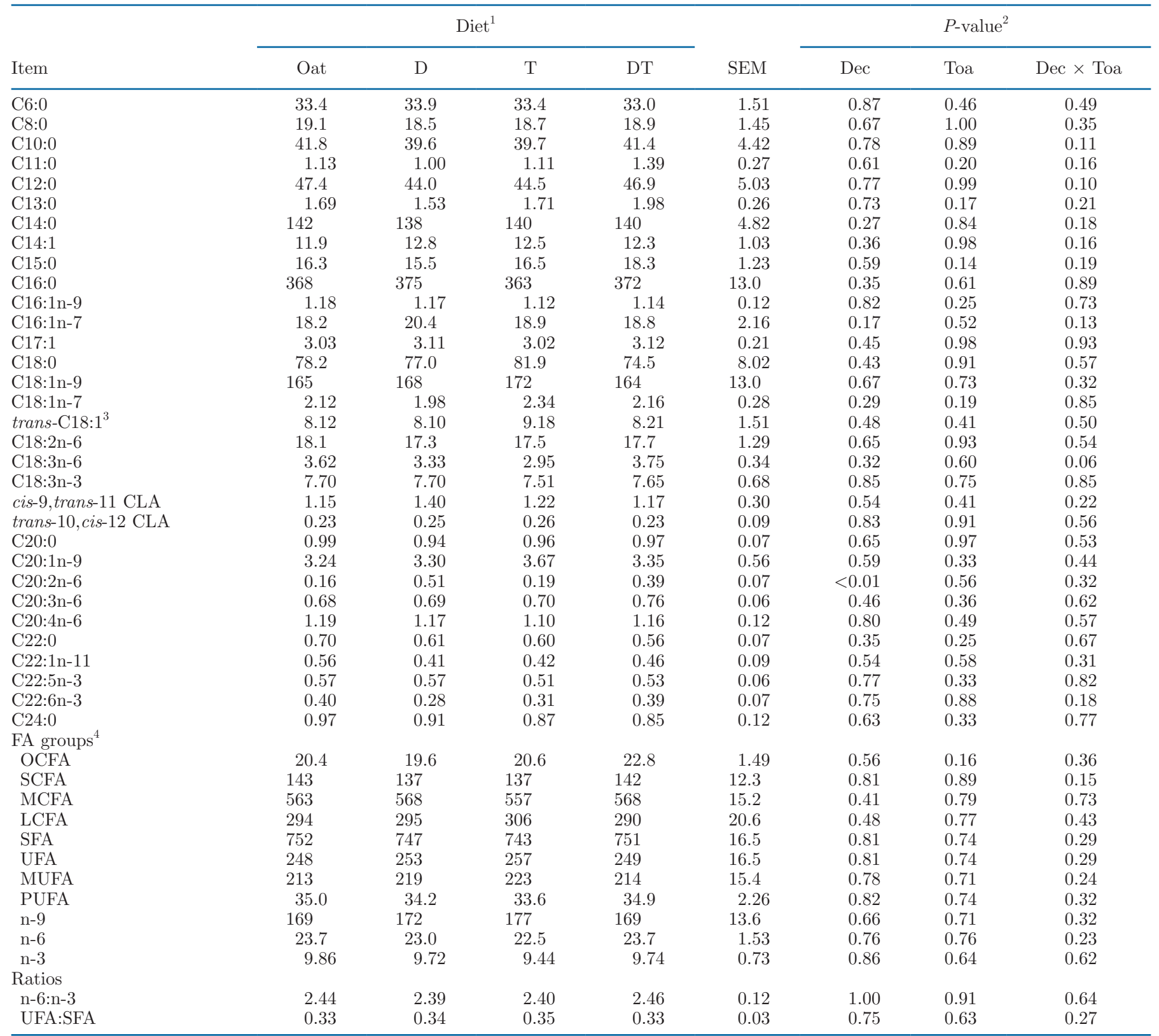

${ }^{1}$ Oat $=$ whole grain oat; $\mathrm{D}=$ decorticated oat; $\mathrm{T}=$ toasted oat; DT $=$ decorticated and toasted oat.

${ }^{2}$ Dec $=$ effect of decortication; Toa $=$ effect of toasting; Dec $\times$ Toa $=$ interaction between toasting and decortication.

${ }^{3}$ All trans-C18:1, mainly vaccenic acid.

${ }^{4} \mathrm{OCFA}=$ odd-chain FA, SCFA = short-chain FA (C6 to C12), MCFA = medium-chain FA (C14 to C17), LCFA = long-chain FA $(\geq \mathrm{C} 18)$.

ibility of FA, supposedly due to microbial BH of UFA, possible absorption of FA in the hindgut (Glasser et al., 2008), and de novo FA synthesis by the hindgut microbes (Boerman et al., 2015). The reduced hindgut digestibility of SFA, such as C18:0, C20:0, and C24:0, and total SFA by decortication could be an explanation for the possible $\mathrm{BH}$ of their unsaturated isomers in hindgut. In addition, hindgut digestibility of C18:1n-9 increased by toasting, which could also be due to $\mathrm{BH}$ or absorption (Glasser et al., 2008). However, the hindgut absorption of FA was negligible based on our results, implying that for the true digestibility of individual FA, the feed-ileum digestibility is more representative than total-tract digestibility, which agrees with Boerman et al. (2015). The results of total-tract FA digestibility obtained from the current study were in the same range 
as those of other studies (Møller, 1989; Avila et al., 2000; Loor et al., 2002). The increased total-tract digestibility of FA due to toasting was the consequence of increased total-tract digestibility of SFA such as C16:0, C18:0, C20:0, C22:0, and C24:0.

The tendency of decortication to increase the small intestinal digested FA could be explained by the increased FA flow at the duodenum due to decortication. The increased FA digestibility in the small intestine $(\mathrm{g} /$ $\mathrm{kg}$ of duodenal FA) by toasting might be a result of an increased UFA:SFA ratio of duodenal FA. A higher intestinal digestibility of UFA than of SFA in ruminants has also been found in earlier studies (Jenkins and Jenny, 1989; Weisbjerg et al., 1992c). Based on a meta-analysis, the increased quantity of $\mathrm{C} 16: 0$ reaching the small intestine positively influences small intestinal digestibility of FA, whereas increased flow of FA at the duodenum has a negative effect on it (Boerman et al., 2015). Accordingly, in our study the duodenal flow of FA decreased with a consequent increase in small intestinal digestibility by toasting, although the proportion of C16:0 in the intake FA was reduced.

Decortication increased the C18:1n-9 proportion in the FA intake and increased its ruminal disappearance due to BH. This could also be seen from the reduced proportion of C18:1n-9 in the duodenal FA and increased ruminal formation of trans-C18:1 isomers. This is consistent with Weisbjerg et al. (1992a), who reported an increased ruminal BH of C18:1n-9 upon its increased intake. Accordingly, it was previously shown that the in vitro $\mathrm{BH}$ of $\mathrm{C} 18: 1 \mathrm{n}-9$ was associated with the formation of several positional isomers such as trans-C18:1, rather than only C18:0 (Mosley et al., 2002; Lejonklev et al., 2013). As FA generally are not fermented in the rumen, increasing the levels of FA intake results in a higher concentration of FA at the duodenum (Børsting et al., 1992; Doreau and Ferlay, 1994).

The reduced formation $(\mathrm{g} / \mathrm{d})$ of $\mathrm{C} 18: 0$ in the rumen by toasting is mainly a reflection of the reduced UFA intake due to toasting because unsaturated $\mathrm{C} 18 \mathrm{FA}$ are precursors for the C18:0 formation. Another reason for this reduction could be due to the reducing effect of toasting on ruminal $\mathrm{BH}$ of $\mathrm{C} 18: 1 \mathrm{n}-9$ and $\mathrm{C} 18: 2 \mathrm{n}-6$ (Reddy et al., 1994), resulting in an increased UFA: SFA ratio in the duodenal FA. The flow of FA from the rumen mainly comprises C18:0 because the majority of C18:2n- 6 and C18:3n-3 is reduced to minor proportions due to extensive BH (Noble, 1978). The trans-C18:1 isomers, mainly vaccenic acid, mostly originate from microbial activity as an intermediate of C18:2n-6 BH (Doreau and Ferlay, 1994), as well as the isomerization of other C18:1 FA (He et al., 2012). Toasting reduced the digested amount of trans-C18:1 isomers in the small intestine as a consequence of its decreased ruminal for- mation, possibly due to the declined BH. Heat treatment was shown to protect UFA against ruminal $\mathrm{BH}$ (Privé et al., 2010; Lashkari et al., 2017; Chowdhury et al., 2018), probably by inducing denaturation of the protein matrix around the fat droplets and making a protecting encapsulation against ruminal $\mathrm{BH}$, resulting in an increased supply of PUFA to the small intestine (Kennelly, 1996). Conjugated linoleic acids (i.e., cis9,trans-11 and trans-10,cis-12) entering the small intestine mainly originate from microbial $\mathrm{BH}$ of $\mathrm{C} 18: 2 \mathrm{n}-6$ (Noble, 1978; Buccioni et al., 2012). Although ruminal $\mathrm{BH}$ of $\mathrm{C} 18: 2 \mathrm{n}-6$ was reduced by toasting, the unaffected CLA proportion in the duodenal FA could be due to the reduced $\mathrm{C} 18: 2 \mathrm{n}-6$ proportion in the $\mathrm{FA}$ intake due to toasting. This also makes it difficult to derive a realistic conclusion about the reducing effect of toasting on the extent of ruminal $\mathrm{BH}$ of oat FA because a considerable amount of UFA was already lost due to toasting before entering the rumen. In addition, toasting decreased the ruminal disappearance of C18:1n-9 in both amount and proportion $(\mathrm{BH})$.

Aligned with the reduced $\mathrm{BH}$ due to toasting, the duodenal proportion of C18:1n-9 increased, although its proportion in FA intake was reduced, by toasting. Despite the unaffected ruminal $\mathrm{BH}$ of $\mathrm{C} 18: 3 \mathrm{n}-3$ by toasting, the proportion of $\mathrm{C} 18: 3 \mathrm{n}-3$ in the duodenal FA increased. This was probably because toasting increased the proportion of $\mathrm{C} 18: 3 \mathrm{n}-3$ in the FA intake, raising its proportion in the duodenal FA. Decortication decreased the rumen $\mathrm{BH}$ of $\mathrm{C} 18: 3 \mathrm{n}-3$ and reduced its proportion in the duodenal FA, mainly due to the reduced intake of C18:3n-3. Some C18:3n-3 was removed with the hull, causing a decline in the C18:3n-3 proportion of the FA intake. Despite the effect of treatments, unexpected lower $\mathrm{BH}$ of $\mathrm{C} 18: 3 \mathrm{n}-3$ compared with $\mathrm{C} 18$ : $2 \mathrm{n}-6$ in our study could be due to the nature of the oat fat, which is rich in phospholipids (Kaimainen et al., 2012), as BH of C18:3n-3 was shown to be lower when esterified to phospholipids (Lashkari et al., 2019).

The small intestinal digestibility of some SFA, such as C12:0, C15:0, C20:0, and C22:0, increased by decortication, possibly due to the removal of hull. Welch et al. (1983) reported that oat hull mainly contains SFA, and as hulls have low degradability, this might also reduce the digestibility of the FA in the hulls. The results of our study indicated that toasting reduced the small intestinal digestibility of $\mathrm{C} 18: 1 \mathrm{n}-9$ and $\mathrm{C} 18: 2 \mathrm{n}-6$ with the same trend seen for their ruminal BH. Børsting et al. (1992) suggested that UFA are more likely to form micelles inside the small intestine when compared with SFA. In addition, Weisbjerg et al. (1992a) showed that the small intestinal digestibility of $\mathrm{C} 18: 1 \mathrm{n}-9$ and $\mathrm{C} 18$ : $2 \mathrm{n}-6$ is independent from the intake level. Therefore, it might be the case that toasting of oat, in addition to 
reducing the FA concentration, also overprotected the remaining C18:1n-9 and C18:2n-6, reducing their small intestinal digestibility and significantly increasing their concentration in ileal flow (results are not presented). The increased flow of C18:1n-9 and C18:2n-6 at the ileum could explain their increased hindgut digestibility. Toasting reduced the ruminal digestibility of oat AA (Panah et al., 2020a) and ruminal BH of C18:1n-9 and C18:2n-6. The protection by toasting against ruminal $\mathrm{BH}$ might also have resulted in the reduced digestibility of C18:1n-9 and C18:2n-6 in the small intestine, supplying a large amount of $\mathrm{BH}$ in the hindgut. Bainbridge and Kraft (2016) also reported that hindgut digestibility of PUFA from protected echium oil increased as a result of their increased flow to the hindgut. However, the concurrent increased hindgut digestibility of transC18:1 as a BH intermediate and unchanged C18:0 hindgut digestibility due to toasting did not support increased $\mathrm{BH}$ in the hindgut. The interaction between decortication and toasting indicated that the effect of toasting on the small intestinal digestibility was stronger in decorticated oat for both C18:1n-9 and C18:2n -6 . Toasting increased the small intestinal digestibility of SFA, including C15:0, C18:0, C20:0, and C24:0, and tended to increase it for $\mathrm{C} 22: 0$. This might be an effect of an increased UFA proportion in the duodenal FA due to toasting because UFA facilitate the solubility of SFA and micelle formation in the small intestine (Jenkins and Jenny, 1989; Børsting et al., 1992; Bauchart, 1993). Although toasting increased the proportion of C18:0 in the FA intake, it resulted in increased small intestinal digestibility of this FA. This is in conflict with the findings of Weisbjerg et al. (1992a), who reported that small intestinal digestibility of C18:0 decreases with increased intake level. The reason for this difference could be due to the increased UFA in the duodenal FA of the present study, in accordance with Børsting et al. (1992) and Boerman et al. (2015).

In agreement with Weisbjerg et al. (1992a), the results of the present study showed that the small intestinal digestibility of SFA increased from C12:0 to C16:0, and then decreased with increasing chain length, regardless of treatment. Furthermore, the small intestinal digestibility of FA increased with the higher level of unsaturation. Unlike other studies (Weisbjerg et al., 1992a; Boerman et al., 2015), in our study, C18:3n-3 had a lower small intestinal digestibility than C18:2n-6.

\section{Microbial Fatty Acid Synthesis and Composition}

Microbial synthesis of fat and FA were not affected by the diets. However, toasting tended to reduce the FA concentration in the microbial biomass, which is possibly a reflection of a reduced FA intake by toasting.
Consistent with Weisbjerg et al. (1992b), the results of the present study indicate that, except for C18:0, the abundance of other FA in microbial fat depends on their intake levels. This could be seen from the increased proportions of C10:0, C14:0, C16:0, and C18:3n -3 in the FA intake due to toasting, increasing these FA in the microbial FA. The tendency of toasting to reduce the proportion of $\mathrm{C} 18: 1 \mathrm{n}-9$ in the microbial FA is also a reflection of a reduced proportion of C18:1n-9 in the FA intake. Weisbjerg et al. (1992b) showed that C16:0 and C18:0 constitute the major proportion of microbial FA, consistent with the results of the present study. Bauchart et al. (1990) reported that due to extensive $\mathrm{BH}$, there was no correlation between the $\mathrm{C} 18: 3 \mathrm{n}-3$ and C18:2n-6 intakes and their incorporation into microbial FA. However, in our study, the increased proportion of C18:3n-3 in microbial FA was in line with its increase in the FA intake by toasting. Likewise, the tendency for decortication to decrease C18:3n-3 in the microbial FA could be related to the reduced proportion of $\mathrm{C} 18: 3 \mathrm{n}-3$ in the FA intake. Toasting also increased the proportion of OCFA in the microbial FA. Microbial OCFA are formed via elongation of propionate or valerate (Emmanuel, 1974). However, Panah et al. (2020a) did not observe any changes in the propionate and valerate production due to toasting in the present experiment.

\section{C17:0 as an Internal Standard}

Choice of appropriate internal standard for FA analysis of feed and digesta samples has been challenging due to potential errors in determination of the FA content or composition (Jenkins, 2010). In the present study, the applicability of C17:0 as an internal standard on FA quantification was tested because rumen microbes contain around $20 \mathrm{~g} / \mathrm{kg}$ of FA of C17:0, which could compromise the use of $\mathrm{C} 17: 0$ as an internal standard. However, the test showed that the use of $\mathrm{C} 17: 0$ as an internal standard had no significant effect on FA quantification. Therefore, it can also be concluded that in samples with a lower C17:0 proportion (i.e., milk; 5.4-7.2 g/1,000 g of FA; Glasser et al., 2008), the effect of C17:0 as an internal standard will have less of an effect on FA quantification.

\section{CONCLUSIONS}

Decortication of oat increased the supply and digested amount of FA in the small intestine and feed-ileum. Toasting of oat severely decreased the concentration of UFA in the diet, but also reduced the ruminal BH of UFA and increased the small intestinal digestibility of the total FA. Decortication of oat seems to be a proper technology to increase the FA supply in dairy cows, 
whereas toasting cannot be recommended due to the high loss of C18:2n-6 and total FA.

\section{ACKNOWLEDGMENTS}

The authors thank the Danish Milk Levy Fund (Mælkeafgiftsfonden, Aarhus, Denmark) for its financial support, Visti Møller (Gl. Buurholt ApS, Brønderslev, Denmark) for performing decortication, and Jens Peter Jeppesen (Lemvig, Denmark) for toasting of the oat. We also thank department staff, laboratory technicians, barn personnel, and barn technicians Torkild N. Jakobsen and Amin T. Aljundi for their dedicated participation. The authors declare no conflicts of interest in the present study.

\section{REFERENCES}

Åkerlind, M., M. Weisbjerg, T. Eriksson, R. Tøgersen, P. Udén, B. Ólafsson, O. Harstad, and H. Volden. 2011. Feed analyses and digestion methods. Pages 41-54 in NorFor-The Nordic Feed Evaluation System. Springer, New York, NY.

Avila, C. D., E. DePeters, H. Perez-Monti, S. Taylor, and R. Zinn. 2000. Influences of saturation ratio of supplemental dietary fat on digestion and milk yield in dairy cows. J. Dairy Sci. 83:1505-1519. https://doi.org/10.3168/jds.S0022-0302(00)75023-5.

Bainbridge, M., and J. Kraft. 2016. Lipid encapsulation provides insufficient total-tract digestibility to achieve an optimal transfer efficiency of fatty acids to milk fat. PLoS One 11:e0164700. https: //doi.org/10.1371/journal.pone.0164700.

Bates, D., M. Mächler, B. Bolker, and S. Walker. 2015. Fitting linear mixed-effects models using lme4. J. Stat. Soft. 67:1-48. https://doi .org/10.18637/jss.v067.i01.

Bauchart, D. 1993. Lipid absorption and transport in ruminants. J. Dairy Sci. 76:3864-3881. https://doi.org/10.3168/jds.S0022 -0302(93) 77728-0.

Bauchart, D., F. Legay- Carmier, M. Doreau, and B. Gaillard. 1990. Lipid metabolism of liquid-associated and solid-adherent bacteria gin rumen contents of dairy cows offered lipid-supplemented diets. Br. J. Nutr. 63:563-578. https://doi.org/10.1079/BJN19900143.

Blanco-Penedo, I., N. Fall, and U. Emanuelson. 2012. Effects of turning to $100 \%$ organic feed on metabolic status of Swedish organic dairy cows. Livest. Sci. 143:242-248. https://doi.org/10.1016/j .livsci.2011.09.023.

Bligh, E. G., and W. J. Dyer. 1959. A rapid method of total lipid extraction and purification. Can. J. Biochem. Physiol. 37:911-917. https://doi.org/10.1139/o59-099.

Boerman, J. P., J. L. Firkins, N. R. St-Pierre, and A. L. Lock. 2015. Intestinal digestibility of long-chain fatty acids in lactating dairy cows: A meta-analysis and meta-regression. J. Dairy Sci. 98:88898903. https://doi.org/10.3168/jds.2015-9592.

Børsting, C. F., M. R. Weisbjerg, and T. Hvelplund. 1992. Fatty acid digestibility in lactating cows fed increasing amounts of protected vegetable oil, fish oil or saturated fat. Acta Agric. Scand. A Anim. Sci. 42:148-156.

Brask, M., M. R. Weisbjerg, A. L. F. Hellwing, A. Bannink, and P. Lund. 2015. Methane production and diurnal variation measured in dairy cows and predicted from fermentation pattern and nutrient or carbon flow. Animal. 9:1795-1806. https://doi.org/10.1017/ S1751731115001184.

Buccioni, A., M. Decandia, S. Minieri, G. Molle, and A. Cabiddu. 2012. Lipid metabolism in the rumen: New insights on lipolysis and biohydrogenation with an emphasis on the role of endogenous plant factors. Anim. Feed Sci. Technol. 174:1-25. https://doi.org/ 10.1016/j.anifeedsci.2012.02.009.
Butt, M. S., M. Tahir-Nadeem, M. K. I. Khan, R. Shabir, and M. S. Butt. 2008. Oat: Unique among the cereals. Eur. J. Nutr. 47:6879. https://doi.org/10.1007/s00394-008-0698-7.

Chowdhury, M. R., S. Lashkari, S. K. Jensen, M. Ambye-Jensen, and M. R. Weisbjerg . 2018. Effects of heat treatment of green protein on in situ protein disappearance and in vitro fatty acid biohydrogenation. J. Agric. Food Chem. 66:8169-8178. https://doi.org/10 $.1021 /$ acs.jafc.8b02176.

Decker, E. A., D. J. Rose, and D. Stewart. 2014. Processing of oats and the impact of processing operations on nutrition and health benefits. Br. J. Nutr. 112(Suppl. 2):S58-S64. https://doi.org/10 $.1017 /$ S000711451400227X.

Doreau, M., and Y. Chilliard. 1997. Digestion and metabolism of dietary fat in farm animals. Br. J. Nutr. 78:S15-S35. https://doi .org/10.1079/BJN19970132.

Doreau, M., and A. Ferlay. 1994. Digestion and utilisation of fatty acids by ruminants. Anim. Feed Sci. Technol. 45:379-396. https:/ /doi.org/10.1016/0377-8401(94)90039-6.

Emmanuel, B. 1974. On the origin of rumen protozoan fatty acids. Biochim. Biophys. Acta 337:404-413. https://doi.org/10.1016/ 0005-2760(74)90116-7.

Glasser, F., P. Schmidely, D. Sauvant, and M. Doreau. 2008. Digestion of fatty acids in ruminants: A meta-analysis of flows and variation factors: 2. C18 fatty acids. Animal 2:691-704. https://doi.org/10 $.1017 /$ S1751731108002036.

Gonthier, C., A. Mustafa, D. Ouellet, P. Chouinard, R. Berthiaume, and H. Petit. 2005. Feeding micronized and extruded flaxseed to dairy cows: Effects on blood parameters and milk fatty acid composition. J. Dairy Sci. 88:748-756. https://doi.org/10.3168/jds .S0022-0302(05)72738-7.

Hall, C. 2010. Oxidation of cereals and snack products. Pages 369-390 in Oxidation in Foods and Beverages and Antioxidant Applications. E. A. Decker, R. J. Elias, D. J. McClements, ed. Woodhead Publishing, Cambridge, UK.

He, M., K. L. Perfield, H. B. Green, and L. E. Armentano. 2012. Effect of dietary fat blend enriched in oleic or linoleic acid and monensin supplementation on dairy cattle performance, milk fatty acid profiles, and milk fat depression. J. Dairy Sci. 95:1447-1461. https:// doi.org/10.3168/jds.2011-4635.

Jenkins, T. C. 2010. Common analytical errors yielding inaccurate results during analysis of fatty acids in feed and digesta samples. J. Dairy Sci. 93:1170-1174. https://doi.org/10.3168/jds.2009-2509.

Jenkins, T. C., and B. Jenny. 1989. Effect of hydrogenated fat on feed intake, nutrient digestion, and lactation performance of dairy cows. J. Dairy Sci. 72:2316-2324. https://doi.org/10.3168/jds .S0022-0302(89)79363-2.

Jensen, S. K. 2008. Improved Bligh and Dyer extraction procedure. Lipid Technol. 20:280-281. https://doi.org/10.1002/lite.200800074.

Kaimainen, M., S. Ahvenainen, M. Kaariste, E. Järvenpää, M. Kaasalainen, M. Salomäki, J. Salonen, and R. Huopalahti. 2012. Polar lipid fraction from oat (Avena sativa): Characterization and use as an o/w emulsifier. Eur. Food Res. Technol. 235:507-515. https:// doi.org/10.1007/s00217-012-1780-1.

Kennelly, J. J. 1996. The fatty acid composition of milk fat as influenced by feeding oilseeds. Anim. Feed Sci. Technol. 60:137-152. https://doi.org/10.1016/0377-8401(96)00973-X.

Lampi, A.-M., A. Damerau, J. Li, T. Moisio, R. Partanen, P. Forssell, and V. Piironen. 2015. Changes in lipids and volatile compounds of oat flours and extrudates during processing and storage. J. Cereal Sci. 62:102-109. https://doi.org/10.1016/j.jcs.2014.12.011.

Lashkari, S., O. Azizi, and H. Jahani-Azizabadi. 2015. Effects of different processing methods of flaxseed on ruminal degradability and in vitro post-ruminal nutrient disappearance. Arch. Anim. Nutr. 69:177-186. https://doi.org/10.1080/1745039X.2015.1034520.

Lashkari, S., L. Hymøller, and S. K. Jensen. 2017. Ruminal biohydrogenation kinetics of defatted flaxseed and sunflower is affected by heat treatment. J. Agric. Food Chem. 65:8839-8846. https://doi .org/10.1021/acs.jafc.7b03008.

Lashkari, S., M. B. Petersen, and S. K. Jensen. 2019. Rumen biohydrogenation of linoleic and linolenic acids is reduced when esterified to phospholipids or steroids. Food Sci. Nutr. 8:79-87. 
Lejonklev, J., A. C. Storm, M. K. Larsen, G. Mortensen, and M. R. Weisbjerg. 2013. Differences in rate of ruminal hydrogenation of C18 fatty acids in clover and ryegrass. Animal 7:1607-1613. https: //doi.org/10.1017/S1751731113001286.

Loor, J. J., J. H. Herbein, and T. C. Jenkins. 2002. Nutrient digestion, biohydrogenation, and fatty acid profiles in blood plasma and milk fat from lactating Holstein cows fed canola oil or canolamide. Anim. Feed Sci. Technol. 97:65-82. https://doi.org/10.1016/S0377 $-8401(01) 00356-X$.

Martin, H. 1958. Factors in the development of oxidative rancidity in ready-to-eat crisp oat flakes. J. Sci. Food Agric. 9:817-824. https: //doi.org/10.1002/jsfa.2740091208.

Møller, P. D. 1989. Disappearance of long-chain fatty acids in the hindgut of dairy cows. Acta Vet. Scand. Suppl. 86:222-224.

Molteberg, E. L., G. Vogt, A. Nilsson, and W. Frolich. 1995. Effects of storage and heat processing on the content and composition of free fatty acids in oats. Cereal Chem. 72:88-93.

Mosley, E. E., G. L. Powell, M. B. Riley, and T. C. Jenkins. 2002. Microbial biohydrogenation of oleic acid to trans isomers in vitro. J. Lipid Res. 43:290-296.

Myers, W. D., P. Ludden, V. Nayigihugu, and B. Hess. 2004. A procedure for the preparation and quantitative analysis of samples for titanium dioxide. J. Anim. Sci. 82:179-183. https://doi.org/10 $.2527 / 2004.821179 x$.

Noble, R. C. 1978. Digestion, absorption and transport of lipids in ruminant animals. Prog. Lipid Res. 17:55-91. https://doi.org/10 .1016/0079-6832(78)90005-8.

Panah, F. M., S. Lashkari, A. L. Frydendahl Hellwing, M. Larsen, and M. R. Weisbjerg. 2020a. Effects of toasting and decortication of oat on nutrient digestibility in the rumen and small intestine and on amino acid supply in dairy cows. J. Dairy Sci. 103:1484-1499. https://doi.org/10.3168/jds.2019-17142.

Panah, F. M., S. Lashkari, and M. R. Weisbjerg. 2020b. Effect of oat decortication on chemical composition, in vitro digestibility and in situ degradability. J. Anim. Physiol. Anim. Nutr. (Berl.) 104:109-115. https://doi.org/10.1111/jpn.13217.

Peterson, D. M., and D. F. Wood. 1997. Composition and structure of high-oil oat. J. Cereal Sci. 26:121-128. https://doi.org/10.1006/ jcrs.1996.0111.

Pires, A. V., M. L. Eastridge, J. L. Firkins, and Y. C. Lin. 1997 Effects of heat treatment and physical processing of cottonseed on nutrient digestibility and production performance by lactating cows. J. Dairy Sci. 80:1685-1694. https://doi.org/10.3168/jds S0022-0302(97)76100-9.

Privé, F., S. Combes, L. Cauquil, Y. Farizon, F. Enjalbert, and A. Troegeler-Meynadier. 2010. Temperature and duration of heating of sunflower oil affect ruminal biohydrogenation of linoleic acid in vitro. J. Dairy Sci. 93:711-722. https://doi.org/10.3168/jds.2009 -2534 .

Qi, X. G., L. Zhu, C. Wang, H. Zhang, L. Wang, and H. Qian . 2017. Development of standard fingerprints of naked oats using chromatography combined with principal component analysis and cluster analysis. J. Cereal Sci. 74:224-230. https://doi.org/10.1016/j.jcs .2017.02.009
Reddy, P. V., J. L. Morrill, and T. G. Nagaraja. 1994. Release of free fatty acids from raw of processed soybeans and subsequent effects on fiber digestibilities. J. Dairy Sci. 77:3410-3416. https://doi.org/ 10.3168/jds.S0022-0302(94)77283-0.

Round, M. 1988. Oat hulls in pelleted diets for export sheep. Proc. Aust. Soc. Anim. Prod. 17:315.

Schürch, A. F., L. Lloyd, and E. Crampton. 1950. The use of chromic oxide as an index for determining the digestibility of a diet. J. Nutr. 41:629-636. https://doi.org/10.1093/jn/41.4.629.

Schwendel, B. H., P. C. H. Morel, T. J. Wester, M. H. Tavendale, C. Deadman, B. Fong, N. M. Shadbolt, A. Thatcher, and D. E. Otter. 2015. Fatty acid profile differs between organic and conventionally produced cow milk independent of season or milking time. J. Dairy Sci. 98:1411-1425. https://doi.org/10.3168/jds.2014-8322.

Scollan, N., S. Padel, N. Halberg, J. Hermansen, P. Nicholas, M. Rinne, R. Zanoli, W. Zollitsch, and L. Lauwers. 2017. Organic and low-input dairy farming: Avenues to enhance sustainability and competitiveness in the EU. EuroChoices (Uckfield) 16:40-45. https://doi.org/10.1111/1746-692X.12162.

Thode, S. 1999. Bestemmelse af purinderivater (allantoin, urinsyre, hypoxanthin og xanthin) samt kreatinin i urin hos kvæg ved anvendelse af HPLC (In Danish). Intern Rapport no. 127. Danmarks JordbrugsForskning, Foulum, Denmark.

Volden, H. 2011. NorFor-The Nordic Feed Evaluation System. EAAP publication no. 130. Wageningen Academic Publishers, Wageningen, the Netherlands.

Weisbjerg, M. R., C. F. Børsting, and T. Hvelplund. 1992a. Fatty acid metabolism in the digestive tract of lactating cows fed tallow in increasing amounts at two feed levels. Acta Agric. Scand. A Anim. Sci. 42:106-114

Weisbjerg, M. R., C. F. Børsting, and T. Hvelplund. 1992b. The influence of tallow on rumen metabolism, microbial biomass synthesis and fatty acid composition of bacteria and protozoa. Acta Agric. Scand. A Anim. Sci. 42:138-147.

Weisbjerg, M. R., T. Hvelplund, and C. F. Børsting. 1992c. Digestibility of fatty acids in the gastrointestinal tract of dairy cows fed with tallow or saturated fats rich in stearic acid or palmitic acid. Acta Agric. Scand. A Anim. Sci. 42 42:115-120.

Welch, R. W., M. V. Hayward, and D. I. H. Jones . 1983. The composition of oat husk and its variation due to genetic and other factors. J. Sci. Food Agric. 34:417-426. https://doi.org/10.1002/ jsfa. 2740340502.

Zinn, R. A., and F. N. Owens. 1986. A rapid procedure for purine measurement and its use for estimating net ruminal protein synthesis. Can. J. Anim. Sci. 66:157-166. https://doi.org/10.4141/ cjas86-017.

\section{ORCIDS}

Farhad M. Panah () https://orcid.org/0000-0002-6623-1528 Saman Lashkari @ https://orcid.org/0000-0002-2033-7837

Søren Krogh Jensen ( https://orcid.org/0000-0001-9852-4774

Martin Riis Weisbjerg (ㄴ) https://orcid.org/0000-0002-6514-9186 